\title{
Use of Annexin V based Sperm Selection in Assisted Reproduction
}

\author{
Teijeiro Juan Manuel ${ }^{1}$, Munuce María José ${ }^{1}$, Caille Adriana María ${ }^{1}, Z_{\text {Zumoffen Carlos }}{ }^{1}$ and Marini Patricia Estela ${ }^{1,2^{*}}$ \\ ${ }^{1}$ Laboratory of Reproductive Medicine, Biochemical and Pharmaceutical Sciences, National University of Rosario, Argentina \\ ${ }^{2}$ Researcher from National Council for Scientific and Technical Research (CONICET), Rosario, Argentina
}

*Corresponding author: Marini Patricia Estela, Laboratory of Cytogenetics, Laboratory of Reproductive Medicine, Biochemical and Pharmaceutical Sciences, National University of Rosario, Argentina, Tel: 54341-155855626; E-mail: marini@ibr-conicet.gov.ar

Received date: May 11, 2017; Accepted date: May 18, 2017; Published date: May 25, 2017

Copyright: (c) 2017 Manuel TJ, et al. This is an open-access article distributed under the terms of the Creative Commons Attribution License, which permits unrestricted use, distribution, and reproduction in any medium, provided the original author and source are credited.

\begin{abstract}
Innovative methods to select sperm subpopulations with the best fertilizing ability are needed in assisted reproductive techniques (ART) in order to improve fertilization and pregnancy rates, while also considering possible epigenetic effects on the offspring. Molecular based selection methods are searched for, under the premise that they could be an improvement over classical selection by morphology and movement. One of these methods sustains the elimination of sperm that can bind to annexin A5 (ANX V), coupled to paramagnetic beads, through the phosphatidyl-serine exposed on their membranes upon apoptosis. Although reports accumulate about the use of this method, controversy persists as to the benefits of ANX V based sperm selection in ART. In this review we consider the arguments in favour and against this method and conclude that to the moment the evidence does not support MACS regular use in ART.
\end{abstract}

Keywords: Annexin A5; Sperm selection; Assisted reproductive techniques

\section{Novel Concepts in Male Factor Diagnosis and Treatment: Andrological Laboratory Perspectives}

ARTs, which overcome physiological steps to fertilization $[1,2]$ include: intra-uterine insemination (IUI), in vitro fertilization/embryo transfer (IVF-ET), and intracytoplasmic sperm injection/embryo transfer (ICSI-ET) [3]. Since the introduction of ICSI in 1992, it has become the indication in treating severe male factor [4]. Despite that ARTs have worldwide become the treatment of choice in most cases of infertility; current success rates of these procedures remain suboptimal $[5,6]$. Evaluation and assessment of semen is very important for both, diagnosis of infertility status and the selection of the appropriated treatment for each couple. In IVF, spermatozoa must recognize and bind to the zona pellucida, undergo the acrosome reaction, penetrate the zona and fuse with the oolemma to fertilize the egg [2]. Instead, in ICSI, a spermatozoon is directly introduced into the oocyte cytoplasm, bypassing natural and physiological barriers. Therefore, although the success of IVF or ICSI is closely related to semen quality, in ICSI sperm are not challenged to perform most physiological activities. Sperm selection for ICSI is mostly based on morphology and motility of spermatozoa [7]. Thus, sperm with low quality as to DNA condensation or damage, and other non-noticeable defects, might fertilize producing an embryo with developmental issues. Motile spermatozoa provide better results in IVF and ICSI respect to nonmotile, and are necessary for optimal fertilization and pregnancy rates [8], and morphologically abnormal spermatozoa show a negative effect on pre-implantation embryo development [9]. It is generally accepted that standard semen analysis involves the measures of volume, $\mathrm{pH}$, sperm concentration, motility and morphology with strict criteria and should be performed according to the World Health Organization guidelines [10]. However, sometimes thresholds are not able to discriminate between fertile and infertile patients, and have a poor predictive power for the outcome of embryo development [11]. In recent years, the management of male factor has undergone important changes with the introduction of novel concepts, such as sperm apoptosis, and the need of new tests for diagnosis and therapeutic interventions [12]. To this end, some apoptotic markers have been proposed in semen, such as activation of caspases, disruption of mitochondrial transmembrane potential (MMP), externalization of phosphatidyl-serine (PS), and increased DNA fragmentation [13,14]. Despite that higher levels of some of the mentioned factors have been found in infertile patients [15], to the moment their use is limited only to research protocols, with no application in routine andrological laboratories [16]. Several tests were developed to detect damaged DNA and are used to evaluate the proportion of spermatozoa with fragmented DNA. The standardized methods are: the sperm chromatin structure assay (SCSA), the sperm chromatin dispersion (SCD) test, the terminal deoxynucleotidyl transferase mediated deoxyuridine triphosphate nick end labeling (TUNEL) assay and the single cell gel electrophoresis (COMET) assay [17-19]. DNA damage may be produced by excessive ROS and as a part of apoptosis or necrosis. Damaged DNA is associated with a range of adverse clinical outcomes including infertility, abortion and offspring's diseases [20,21]. In a meta-analysis, Zhao et al. [22], demonstrated that high-level of sperm DNA fragmentation has a detrimental effect on outcome of IVF/ICSI, with decreased pregnancy rates and increased miscarriage rates. Moreover, when DNA fragmentation in basal semen exceeds 30\%, ICSI should be the method of choice [23-25]. As good as methods could be to detect sperm quality, techniques are permanently being searched for in order to select those sperm from a semen population that exhibit better fertilizing chances.

\section{Traditional and Advanced Methods of Sperm Preparation for ART}

Efforts are made to develope new methods to select in vitro a sperm subpopulation with the highest fertilizing potential [26,27]. 
Conventional sperm preparation techniques, namely glass wool filtration, SU, and DG are based on the premise that cervical mucus selectively allows only progressively motile sperm of normal shape and size to penetrate and migrate through the cervix [2]. Sperm recovered after glass wool filtration show significantly higher quality than the original ejaculate [28] and acrosomes are mostly intact [29]. Both DG and SU methods for sperm selection were introduced in the last $\left(5^{\text {th }}\right.$ edition) of World Health Organization guidelines [10]. Higher rates of morphologically normal spermatozoa are recovered after DG than SU or glass wool filtration [30]; however, this does not produce significant differences in the fertilization, implantation and pregnancy rates after IVF [30]. Respect to the capacity of DG and SU to clean the whole semen from DNA-damaged spermatozoa, some authors reported that both techniques yield a significantly higher proportion of motile sperm with non-fragmented-DNA in comparison to unprocessed semen [31]. However, others provided evidence that DG increases sperm DNA fragmentation in some subjects (about $50 \%$ of patients), severely affecting pregnancy chances [32].

In our experience, when spermatozoa are incubated for several hours under biological conditions, a common practice during IVF, an increase in oxidative sperm metabolism and in the proportion of fragmented-DNA should be expected as a consequence of sperm's own oxidative metabolism [33]. However, there is some individual susceptibility, in $20-30 \%$ of the patients selection results iatrogenic, suggesting that the particular response of each patient's sperm should be evaluated in a previous cycle [34]. It has become evident that the traditional selection methods are individual-dependent and in some cases inefficient in identifying the most suitable spermatozoa for fertilization. New insights into the molecular biology of sperm have led to the development of molecular selection strategies [35]. Human oocytes are surrounded by hyaluronic acid (HA), which acts as a natural selector of spermatozoa, thus a biological test using HA-coated slides has been developed [36,37].

Bound spermatozoa are selected and used for ICSI, and the procedure is called "physiologic ICSI", PICSI. There are some reports showing that PICSI has a considerably higher chance $(\approx 5$ fold $)$ to achieve pregnancy than ICSI, using sperm selected only by morphology assessment [38,39]. However, a meta-analysis of all available studies showed that although an improvement in embryo quality is sustained for PICSI over ICSI, the evidence is not enough as to justify the routine use of PICSI [40]. Another type of molecular selection method is based on the elimination of those spermatozoa that have begun apoptosis. To this aim, the exposure of PS at early stages of the apoptotic process and the ability of ANX V to selectively bind to exposed PS are used. In one method, ANX V is coupled to a glass wool matrix to produce a solid phase filter, combining the binding ability of ANX V to PS with the glass wool filtering characteristics [41]. However, the top ranking technique based on sperm binding to ANX V is MACS.

\section{Acquisition of Fertilizing Capacity by Human Sperm}

The mammalian spermatozoa are not capable of fertilizing oocytes immediately after ejaculation. Physiological changes that allow them to fertilize occur during their transit through the female genital tract $[1,2]$ and are completed in the oviduct, and are collectively known as capacitation [42,43]. Capacitation consists of several changes in spermatozoa such as removal and modification of many surface proteins, changes in the oxidative metabolism, changes in the pattern of movement (hyperactivated motility), efflux of cholesterol from the membranes, membrane scramble and modification of the phosphotyrosine content of several proteins [2,44]. Despite capacitation takes place in vivo, it can also be achieved by incubation of spermatozoa in vitro at body temperature, using physiologically based media [45]. Some of the events that occur during sperm capacitation are shared with other processes as apoptosis-programmed cell death. It is generally accepted that in the capacitation process reactive oxygen species (ROS) are generated, and stimulate intracellular cAMP generation followed by inhibition of tyrosine phosphatase activity and by tyrosine protein phosphorylation $[46,47]$. However, under stress conditions, excessive ROS generation would eventually result in activation of the apoptotic cascade, characterized by enhanced mitochondrial ROS generation, capsize activation, PS externalization, lipid peroxidation and motility loss $[48,49]$. Studies on capsize activation show that capsize 3 is present in human sperm and may function to increase PS externalization and DNA fragmentation [50]. Caspases 1, 8 and 9 are also present in sperm and are associated with changes in the cell membrane that include PS exposure. On the other hand, some studies suggest that sperm apoptosis can proceed via a capsize-independent pathway [51,52]. Then, membrane scramble and PS exposure occur during apoptosis and also upon capacitation, and PS exposure on live sperm cells has been considered a sign of capacitating ability, directly related to fertilizing chances [53]. In addition, necrosis produced by certain pathological conditions may also produce ROS and thus, PS translocation [54]. All these events are also prone to occur in a population of sperm subjected to manipulation in vitro.

\section{Understanding the Use of Annexin V in Sperm Selection}

The annexins constitute a family of calcium-dependent membranebinding proteins [55] which due to the ability to bind to and hold together certain biological structures were named annexins, a term derived from the Greek annex meaning "bring/hold together" [56]. The members of the annexin family share the property of calciumdependent binding to membranes containing negatively charged phospholipids [57-59]. ANX V was first isolated as a vascular anticoagulant [60] and has a high calcium-dependent binding affinity for negatively charged phospholipids as PS [60-62]. ANX V binding to PS liposomes requires 10 to $100 \mathrm{M}$ of $\mathrm{Ca}^{2+}$ and the binding surface area is of 59 phospholipid molecules per protein. Further, the plication serine displaces bound annexins, supporting the hypothesis that this binding is of ionic nature [63]. As revealed by X-ray crystallography, ANX V tertiary structure consists of a core of four domains that are arranged in a cyclic way, which gives the molecule a slightly curved shape with a convex and a concave face (Figure 1). The Ca2+ and PS binding sites are located at the convex, membrane-facing side of the protein [64].

Data obtained from crystallography provide evidence that the interfacial basic cluster is the place for dimerization of molecules of ANX V, which is synergistically coupled to membrane phospholipid binding [65]. The lipid bilayer shows a bent shape and contains a concave region in the annexin-membrane interaction interface, which supports the idea that ANX V could disturb the stability of lipids and bend membranes [66]. Cell injury leads to redistribution of lipids within the plasma membrane resulting in surface exposure of PS and phosphatidylethanolamine (PE) [67] and phospholipid scramblase activity produces a collapse of phospholipid asymmetry with externalization of PS [68]. The physiological functions known for 
externalized PS are: (1) control of the hemostatic balance, since several pro-coagulant as well as anticoagulant reactions require PS-containing lipid surfaces [69], and (2) mediating recognition and clearance of apoptotic cells by phagocytic cells, to prevent release of the inflammatory cell content upon cell lysis [70]. The asymmetry of plasma membrane phospholipids is maintained by an aminophospholipid translocase that transports PS and PE from the outer to the inner membrane leaflets [67], thus the exposure of PS results from a balance between aminophospholipid translocase and scramblase activities [71]. TMEM16F, a scramblase regulated by elevated intracellular $\mathrm{Ca} 2+$ and XKR8, a caspase-sensitive protein, have been recently identified as required for PS exposure in apoptotic cells [72]. deVries et al. [51] found an isoform of phospholipid scramblase (PLSCR) homogeneously distributed in human sperm cells, which is activated by bicarbonate and associated to protein kinase A function and is caspase-independent. Recently, transmembrane protein 16E (TMEM16E) has been identified in mouse sperm tail, and its function as a PLSCR at inner membranes involved in sperm motility was proposed [73]. Apoptosis in spermatozoa is considered to be different from the process in somatic cells, due to the particularities of these cells as scarce cytoplasm and organelles and transcriptional inactivity, and is still poorly understood [48]. Between de apoptotic phenomena produced in human spermatozoa are PS externalization, caspase activation, loss of MMP and DNA fragmentation [74]. During apoptosis, the increase of ROS in mitochondria produces lipid peroxidation, with a concomitant loss of sperm motility, also related to effects on the electron transport chain proteins in the mitochondria [75]. When using MACS, PS apoptotic sperm are eliminated. However, PS exposure also occurs during sperm capacitation, independently of the activation of apoptotic mechanisms [51]. Although sperm capacitation is irrelevant when using ICSI, the events that follow sperm entry to the oocyte also require correct sperm function, and the ability to capacitate is related to sperm physiological quality [53].

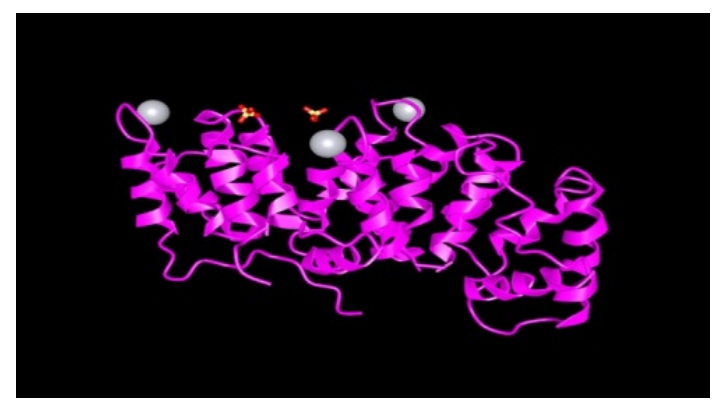

Figure 1: Crystal and molecular structure of human Annexin V after refinement. Yellow-ro osses indicate sulfate ions. Grey spheres show calcium ions.

\section{How does MACS Work?}

The principle of ANX V binding for cell discrimination was initially applied in the immunology field to isolate red blood cells from lymphocytes [76,77]. This approach was developed and commercialized by MiltenyiBiotec $\mathrm{GmbH}$ for sperm samples (BergischGladbach, Germany [78]). MACS is based on the binding of colloidal superparamagnetic microbeads ( $50 \mathrm{~nm}$ diameter) coupled to ANX V to externalized PS of the plasma membrane of sperm with activated apoptosis pathway signaling [79]. Thus, apoptotic and other
PS exposing (EPS) cells can be depleted from the whole sample. Sperm presenting such translocation on their membranes bind to the microspheres-ANX V. The sperm/micro-beads suspension is then loaded on top of a separation column, which is placed in a fitted magnet. ANX V bound sperm stay trapped in the matrix, and the separation process would give two sperm populations: EPS-negative (vital, non-apoptotic sperm with intact membranes) and EPS-positive [80]. Electron microscopy has revealed microbead's binding on membranes at the acrosomal and postacrosomal regions only in EPSpositive and not in the EPS-negative sperm fraction [81]. The EPSpositive fraction contains the apoptotic sperm population, but the ANX V-conjugated microbeads may also label dead cells, cells with acrosome reacted sperm [79] and sperm that have begun capacitation [51]. MACS use involves the passage of sperm through a high power static magnetic field (SMF) of $0.5 \mathrm{~T}$ and up to $1.5 \mathrm{~T}[82,83]$. Several researches have shown that SMF can generate some kind of effect on biological systems, as pro-inflammatory changes and increase in the generation of ROS [84-86], which is highly detrimental to sperm. Although the mechanism by which SMF affects cells is not well understood, some reports speculate that it might increase the activity, concentration, and life time of paramagnetic free radicals, which could ultimately produce oxidative stress, genetic mutations, and/or apoptosis [87-89]. Thus, the concentration and/or lifetime of free radicals that escape from the radical pair would increase by exposure to SMF, and free radicals initiate membrane lipids, proteins and DNA damage, and may lead to apoptosis or necrosis $[89,90]$. The diversity of alterations reported for SMF exposure may be related to varied duration, intensity, tissue penetration, and the type of cells [86,91]. In reproductive tissues, SMF has been shown to modulate the activity of several enzymes related to oxidative stress in the testicles of exposed rats [92]. Studies in model animals and humans exposed to magnetic fields show varied effects on spermatogenesis that range from no effect to severe alterations [93-98]. Instead, there is consistency about detrimental effects on embryos and development, upon animal exposure during spermatogenesis $[99,100]$. Although there are few reports about the effects of SMF direct action on human sperm cells [97], the biological alterations reported in other systems race an alarm about its application on spermatozoa used for ARTs, particularly ICSI where posterior sperm function is not challenged.

\section{In vitro studies on the Quality of Sperm Selected by MACS}

A cumulous of studies has been done in order to analyze the effect of MACS selection on the quality of sperm in vitro. As mentioned, apoptosis in sperm is speculated to show particular characteristics, however, some submicroscopic features typical for apoptosis of somatic cells have been described in sperm [101] and the transference of PS from the inner to the outer membrane is considered to occur as a sign of early apoptosis. An interesting analysis was performed in this regard, by assessing for PS exposure by ANX V binding and for vitality with propidium iodide (PI) stains [53]. In this study ANX V-positive PI-negative sperm were considered with signs of capacitation; while ANX V-positive PI negative spermatozoa were related to apoptosis. According to this idea, depleting semen samples from spermatozoa with EPS, might discard not only apoptotic cells but also spermatozoa that have begun capacitation.

Some early studies concerning MACS use in sperm preparation for ART, assayed motility, viability, morphology and markers of apoptosis (levels of active caspase-3, MMP and EPS) in semen samples from 
healthy donors $(n=15)$ [102]. The results showed that the combination of DG and MACS was superior to all other sperm preparation methods in terms of providing motile, viable and non-apoptotic spermatozoa, supporting the incorporation of MACS to actual protocols. Studying sperm selection by MACS in 29 selected normozoospermic semen samples, combining DG with MACS was analyzed, and the nuclear parameters DNA fragmentation index and protamine deficiency were measured [103]. It was found that selection by each of the techniques alone (DG or MACS) significantly decreased the DNA fragmentation index and the protamine deficiency. However, the combination of DG and MACS allowed isolating high-quality sperm with higher DNA integrity and lower protamine deficiency than any of the methods alone. Morphological evaluation of sperm selected by SU followed by MACS was performed by electronic microscopy using samples from infertile men [101]. Although the number of spermatozoa with characteristics compatible with cell death diminished after the selection process, no significant differences were noted when the SU/ MACS semen fractions were compared with SU alone. Moreover, as expected, the number of spermatozoa was reduced by the additional selection step, and MACS did not eliminate spermatozoa with uncondensed and vacuolated chromatin, which may represent immature cells [101]. Bucar et al. [104] evaluated sperm DNA fragmentation in semen samples $(\mathrm{n}=100)$ processed by several combinations of MACS, DG and SU techniques. They showed that MACS decreased the DNA fragmentation rates when performed before DG and SU, especially in samples with low values of progressive motility, vitality and hypoosmotic swelling test. Also, groups DG-SU, DG-MACS-SU, DG-SU-MACS and MACS-SU presented a significant decrease in DNA fragmentation, but the highest reduction rate was obtained with MACS-DG-SU. In accordance with previous results, DNA fragmentation negatively correlated with sperm vitality, membrane integrity and progressive motility. The authors suggested that this combination of methods could be applied to sperm samples with low motility, viability and membrane integrity. However, the increase of manipulation steps and time are not recommended in sperm processing for ART. In a recent study using normozoospermic $(n=10)$ and oligozoospermic $(n=10)$ semen samples, a comparison was done between selection by SU and DG alone or combined with MACS [105]. In this case, no statistically significant level was found, but the authors reported improved aspects when adding the MACS step, although it also produced a significant loss in the numbers of total and rapid progressive spermatozoa. When studying samples from three categories: normozoospermic $(n=13)$, asthenoteratozoospermic $(n=17)$ and teratozoospermic $(\mathrm{n}=12)$, for chromatin quality and improvement by DGC-MACS, Delbes et al. [106] found that compared with normozoospermic samples, raw asthenoteratozoospermic and teratozoospermic samples had a higher proportion of spermatozoa containing DNA breaks, but only sperm from asthenoteratozoospermic samples exhibited altered chromatin structure and decreased binding to hyaluronic acid. The analysis showed that DG appeared to select for more mature spermatozoa with high DNA compaction, and all three categories of sperm were enriched on spermatozoa with good chromatin quality after DG-MACS. Another parameter analyzed upon selection of sperm from infertile patients was the MMP [107]. A combination of MACS with DG allowed a significant reduction of $70 \%$ sperm exposing PS and of $60 \%$ sperm with disrupted MMP, which also provided a mean increase of $50 \%$ in sperm survival at $24 \mathrm{~h}$, that is, DG plus MACS resulted in improved sperm long term viability, motility and mitochondrial membrane integrity. Studying patients with unexplained infertility, and with unsuccessful intrauterine insemination, Lee et al. [108] showed that not only MACS selection provided spermatozoa with significantly reduced apoptotic markers respect to DG, but also with improved induced acrosome reaction rates. However, motility was slightly decreased. Yet another study using samples from men attending the andrology laboratory $(n=25)$ analyzed DNA fragmentation after DGMACS or DG-SU [83]. In this case, SU method provided sperm of higher quality in terms of motility, morphology and extent of DNA fragmentation compared to MACS, after DG. As most reports about the efficiency of MACS selection evaluate sperm post DG, and DG induces EPS due to capacitation and acrosome reaction, Tavalaee et al. [109] assayed the role of MACS before DG (MACS-DG) and MACS after DG (DG-MACS) using semen samples from 15 infertile men. Under these conditions, DG resulted more efficient than MACS in separating intact sperm only in terms of normal morphology, DNA and chromatin integrity but not for active caspase, and a combination of sperm selection methods was more efficient than a single procedure. Also, combined procedures showed higher efficiency to separate sperm with active caspase but only in the MACS-DG group. The use of MACS in relation to aneuploidy has also been considered. In ejaculates from normozoospermic patients with implantation failure, aneuploid, apoptotic and DNA-injured spermatozoa decreased significantly after MACS [110]. However, the interactions between apoptotic markers, DNA integrity and aneuploidy and the effect of MACS on these parameters remain unknown [110]. Other study was conducted in order to determine the fertilization potential of selected sperm $(n=35)$ by hamster oocyte penetration and hamster oocyte-intracytoplasmic sperm injection [111]. ANX V-negative sperm, showing higher motility, lower caspase 3 activation, better mitochondrial membrane integrity and smaller extent of DNA fragmentation than ANX Vpositive ones; had higher oocyte penetration capacity, but comparable sperm chromatin decondensation following ICSI. Thus, while oocyte penetration was favored in selected sperm, posterior steps in fertilization, as chromatin decondensation did not correlate with PS exposure/MACS selection. As seen, despite the huge bibliography on in vitro assays related to MACS use, discrepancy about the benefits persists. Some studies have been done considering particular health situations. The presence of varicocele in patients was taken into account and analysis of semen samples $(n=36)$ was performed by DG followed by MACS. Semen parameters of varicocele men are usually suspected to exhibit higher levels of abnormalities including DNA fragmentation, ROS and apoptotic markers. After MACS, samples showed no deleterious reduction in total sperm motility while sperm DNA fragmentation was significantly reduced [112]. Thus, this selection method may be particularly useful in infertility due to varicocele. Also, exposure of men to some environmental hazards as manganese and phthalates has been shown to increase sperm apoptosis $[113,114]$. The use of MACS may prove useful for these patients, and the same may be thought for patients with extreme high sperm DNA fragmentation. Another particular situation in which selection of high quality sperm may be of use is cryopreservation. Sperm cryopreservation is frequently used among young cancer patients facing chemotherapy. Although sperm cryopreservation methods are under constant study and improvement, higher efficacy is still needed. The use of MACS to improve cryopreservation-thawing protocols has been analyzed showing higher cryosurvival rates [115], a 3 times increase in intact mitochondria (10 healthy donors) [116] and lower caspase activation [117] for selected sperm. These results are summarized in Table 1. 
Citation: Manuel TJ, José MM, María CA, Carlos Z, Estela MP (2017) Use of Annexin V based Sperm Selection in Assisted Reproduction.

\begin{tabular}{|c|c|c|c|c|}
\hline Reference & Selection procedure & Semen Quality (n) & Assessed parameters & Result \\
\hline$[81] \uparrow$ & $\begin{array}{l}\text { Sperm binding to ANX } \vee \text { coupled } \\
\text { beads }\end{array}$ & $\begin{array}{l}\text { Normal ( } \mathrm{n}=68 \text { from } 15 \text { donors and } 25 \\
\text { patients) }\end{array}$ & $\begin{array}{l}\text { Morphological evaluation by } \\
\text { electronic microscopy }\end{array}$ & $\begin{array}{l}\text { Bead binding only to EPS } \\
\text { sperm }\end{array}$ \\
\hline$[117] \uparrow$ & Cryopreservation-MACS & Normal ( $n=40$ from 10 donors) & Caspase activation & $\begin{array}{l}\text { Decreased activated caspases } \\
8,9,1 \text { or } 3\end{array}$ \\
\hline$[80] \uparrow$ & Cryopreservation-MACS & Normal $(n=15)$ & $\begin{array}{l}\text { Membrane changes, CD95 } \\
\text { (Fas, APO-1), caspases, } \\
\text { viability, objective motility }\end{array}$ & Non-apoptotic enrichment \\
\hline$[116] \uparrow$ & MACS-Cryopreservation & Normal $(n=10)$ & MMP & Increased intact mitochondria \\
\hline$[101] \uparrow$ & SU-MACS vs. SU & Infertile men & $\begin{array}{l}\text { Morphological evaluation by } \\
\text { electronic microscopy }\end{array}$ & $\begin{array}{l}\text { Reduced number of sperm, } \\
\text { presence of immature cells }\end{array}$ \\
\hline$[109] \uparrow \downarrow$ & MACS-DG vs. DG-MACS vs. DG & $\begin{array}{l}\text { Infertile men } \\
(n=15)\end{array}$ & $\begin{array}{l}\begin{array}{l}\text { Morphology, } \\
\text { chromatin } \\
\text { caspase }\end{array} \\
\text { integrity, }\end{array}$ & $\begin{array}{l}\text { Decreased normal morphology, } \\
\text { intact DNA and chromatin } \\
\text { integrity, better caspase rates } \\
\text { for combined methods }\end{array}$ \\
\hline$[102] \uparrow$ & $\begin{array}{l}\text { DG-MACS vs. DG, wash, wash } \\
\text { +MACS }\end{array}$ & Normal $(n=15)$ & $\begin{array}{l}\text { Motility, viability, } \\
\text { markers of } \begin{array}{r}\text { aphology, } \\
\text { (caspase-3, MMP, EPS) }\end{array}\end{array}$ & $\begin{array}{l}\text { Improved motility and viability, } \\
\text { increase of non-apoptotic } \\
\text { spermatozoa }\end{array}$ \\
\hline$[115] \uparrow$ & Cryopreservation-MACS & Normal $(n=29)$ & Cryosurvival rates & Improved \\
\hline$[103] \uparrow$ & DGC-MACS vs. DG or MACS & Normal $(n=29)$ & DNA fragmentation, protamine & Improved nuclear parameters \\
\hline$[104] \uparrow$ & $\begin{array}{l}\text { MACS-DG-SU vs. combinations } \\
\text { of MACS, DG and SU }\end{array}$ & Semen samples $(n=100)$ & $\begin{array}{l}\text { DNA fragmentation } \\
\text { Vitality, membrane integrity and } \\
\text { progressive motility }\end{array}$ & $\begin{array}{l}\text { MACS-DG-SU shows the } \\
\text { highest improvement for all the } \\
\text { measured characteristics }\end{array}$ \\
\hline$[105] \downarrow$ & $\begin{array}{l}\text { SU-MACS vs. } \\
\text { DG-MACS vs. SU vs. DG }\end{array}$ & $\begin{array}{l}\text { Normal }(n=10) \text { and Oligozoospermic } \\
(n=10)\end{array}$ & $\begin{array}{l}\text { Morphology, motility, DNA } \\
\text { integrity, levels of Izumo-1 and } \\
\text { PLCZ proteins }\end{array}$ & Non-significant results \\
\hline$[106] \uparrow$ & DG-MACS vs. DG & $\begin{array}{ll}\text { Normal } & (n=13), \\
\text { asthenoteratozoospermic } & (n=17), \\
\text { teratozoospermic }(n=12) & \end{array}$ & $\begin{array}{l}\text { Chromatin quality (DNA } \\
\text { fragmentation, compactation) }\end{array}$ & $\begin{array}{l}\text { Enriched chromatin quality for } \\
\text { all sperm categories }\end{array}$ \\
\hline$[107] \uparrow$ & DG-MACS & Infertile patients & MMP and survival at $24 \mathrm{~h}$ & $\begin{array}{l}\text { Improved long term viability, } \\
\text { motility and mitochondrial } \\
\text { membrane integrity }\end{array}$ \\
\hline [108] & MACS vs. DG & $\begin{array}{l}\text { Unexplained infertility and with } \\
\text { unsuccessful intrauterine insemination }\end{array}$ & $\begin{array}{l}\text { Apoptotic markers, motility, } \\
\text { apoptosis, induced acrosome } \\
\text { reaction }\end{array}$ & $\begin{array}{l}\text { Reduced apoptotic reduced } \\
\text { motility and apoptotic markers, } \\
\text { improved induced AR rates }\end{array}$ \\
\hline$[83] \downarrow$ & DG-MACS vs. DG-SU & Semen samples $(n=25)$ & $\begin{array}{l}\text { DNA fragmentation, motility, } \\
\text { morphology }\end{array}$ & $\begin{array}{l}\text { Lower motility, } \quad \text { worst } \\
\text { morphology, higher } \\
\text { fragmentation }\end{array}$ \\
\hline$[110] \uparrow$ & MACS & Normal with implantation failure $(n=6)$ & $\begin{array}{l}\text { Aneuploidy, apoptotosis, DNA } \\
\text { fragmentation }\end{array}$ & Significantly decreased \\
\hline$[111] \uparrow$ & MACS & Normal $(n=35)$ & $\begin{array}{lrr}\text { Motility, } & \text { caspase } 3 & \text { activation, } \\
\text { MMP, DNA } & \text { fragmentation, } \\
\text { Hamster } & \text { oocyte } & \text { penetration } \\
\text { and } & \text { hamster } & \text { oocyte- } \\
\text { intracytoplasmic sperm injection }\end{array}$ & $\begin{array}{l}\text { improved motility, caspase } 3 \\
\text { level, MMP, DNA integrity, } \\
\text { oocyte penetration; comparable } \\
\text { sperm chromatin } \\
\text { decondensation following ICSI }\end{array}$ \\
\hline$[112] \uparrow$ & DG-MACS & Varicocele patients $(n=36)$ & $\begin{array}{l}\text { Motility, DNA fragmentation, } \\
\text { ROS, apoptotic markers }\end{array}$ & $\begin{array}{l}\text { No effects on motility, } \\
\text { decreased DNA fragmentation }\end{array}$ \\
\hline$[113,11 \uparrow$ & MACS & $\begin{array}{l}\text { Men exposed to environmental } \\
\text { hazards as manganese and phthalates }\end{array}$ & Apoptosis, DNA damage & $\begin{array}{l}\text { Decreased } \\
\text { parameters }\end{array}$ \\
\hline
\end{tabular}

Table 1: Results of in vitro analysis of sperm upon MACS selection, Arrows pointing up and down represent increased and decreased sperm quality after MACS selection, respectively. 


\section{Reproductive outcome of MACS use in ART}

In vitro studies about sperm improvement after MACS seem to encourage the use of this technique, at least for semen samples with some particularities and keeping in mind possible diminution of the number and motility of spermatozoa. Based on this, diverse fertilization analyses (summarized in Table 2) have been made in order to gain conclusive results about the use of MACS in ART. The reports are composed of trials in which MACS is followed by ICSI, as the main objective is to overcome severe male factor.

\begin{tabular}{|c|c|c|c|c|}
\hline Reference & $\begin{array}{l}\text { Sperm selection method } \\
\text { (n) }\end{array}$ & Population & Parameters assessed & Result \\
\hline [118] & $\operatorname{MACS}(n=1)$ & $\begin{array}{l}\text { AT semen with high fragmentation index } \\
\text { and cleaved caspase } 3 \text { rates- } \\
\text { reproductively healthy mother }\end{array}$ & Live birth & Born of a healthy baby \\
\hline [119] & $\operatorname{MACS}(n=1)$ & $\begin{array}{l}\text { 1-AT and high DNA fragmentation 2- } \\
\text { abnormal morphology and caspases- } \\
\text { donor oocytes }\end{array}$ & Pregnancy & Advanced pregnancies achieved \\
\hline [122] & $\begin{array}{l}\text { MACS }(n=123) \text { vs. wash } \\
(n=114)\end{array}$ & Unselected men-donated oocytes & $\begin{array}{l}\text { Fertilizatio, } \quad \text { implantation, } \\
\text { pregnancy, and live-birth rates }\end{array}$ & No significant differences \\
\hline [123] & $\begin{array}{lll}\text { MACS } & (n=122) & \text { vs. } \\
(n=74) & & \end{array}$ & OligoaAT & $\begin{array}{l}\text { Pregnancy and cleavage rates } \\
\text { sperm morphology }\end{array}$ & $\begin{array}{l}\text { Improved sperm morphology, slightly } \\
\text { higher implantation rate }\end{array}$ \\
\hline [124] & $\begin{array}{l}\text { DG-MACS }(n=37) \text { vs. DG } \\
(n=37)\end{array}$ & Unexplained infertility & $\begin{array}{l}\text { Fertilization (pro-nuclei), } \\
\text { cleavage rate, embryo quality, } \\
\text { pregnancy, birth }\end{array}$ & $\begin{array}{l}\text { Higher fertilization rate and 8-cells, day } \\
3 \text { embryos/oocyte, non-significant } \\
\text { differences in pregnancy and birth } \\
\text { rates }\end{array}$ \\
\hline [125] & $\begin{array}{l}\text { DG-MACS vs. DG-HA vs. } \\
\text { DG (total } n=136 \text { ) }\end{array}$ & Normal semen, infertile couples & $\begin{array}{l}\text { Embryo quantity and quality, } \\
\text { fertilization and pregnancy } \\
\text { rates }\end{array}$ & Higher clinical pregnancy rates \\
\hline [126] & $\begin{array}{l}\text { MACS vs. SU vs. DG } \\
(\mathrm{n}=499)\end{array}$ & $\begin{array}{l}\text { Systematic review and meta-analysis of } \\
\text { prospective randomized trials }\end{array}$ & $\begin{array}{l}\text { Pregnancy, implantation and } \\
\text { miscarriage rates }\end{array}$ & Increased pregnancy rates \\
\hline [127] & $\begin{array}{l}\text { Cryopreservation-MACS } \\
(n=1)\end{array}$ & $\begin{array}{l}\text { Cryopreserved spermatozoa with high } \\
\text { DNA damage from a cancer patient }\end{array}$ & Pregnancy & Birth of healthy twins \\
\hline [128] & TESA-MACS $(n=1)$ & Apoptosis in testicles & Pregnancy & Birth and normal 4 years development \\
\hline
\end{tabular}

Table 2: Fertilization evidence of MACS use, In all the studies sperm selection was followed by ICSI. AT: asthenoteratozoospermic. Arrows pointing up and down represent increased and decreased outcome in ART after MACS selection, respectively.

The initial information was mostly case reports, centered in achieving a pregnancy and a healthy newborn. In this regard, in 2010 [118], the successful use of MACS-ICSI and the born of a healthy baby, using semen from a asthenoteratozoospermic patient, with high fragmentation index (30\%, TUNEL) and high cleaved caspase 3 rate (8\%), and oocytes from the reproductively healthy mother was informed. Also in 2010, two cases were reported of successful advanced pregnancies achieved by MACS-ICSI with semen from a patient with asthenoteratozoospermia and abnormal DNA fragmentation (TUNEL 30\%), and other with high rate of abnormal morphology (5\% normal forms according to Kruger) and abnormal active caspase-3 (16\%) [119]. It is to consider that in this last study donated oocytes were used. Oocytes, particularly when provided by young women, show the ability to repair DNA damage through the expression of genes responsible for this activity in both parental genomes, after fertilization [120]. Thus, although oocyte donation is prescribed to avoid the bias related to oocyte quality; the ability of the female gamete to repair moderate DNA damage in the sperm genome [121], which correlates with the last stages of apoptosis, must be considered when making conclusions about the results of sperm selection based on apoptosis or DNA fragmentation.

Also using donated oocytes, an interesting analysis was performed with unselected men semen samples $(n=237$ men) comparing the results of ICSI $(n=114)$ and MACS-ICSI $(n=123)$ [122]. No significant differences were found in the mean fertilization rates, or in implantation, pregnancy, and live-birth rates. And slight but not statistically significant differences were noted in the qualities observed in the early embryos, favoring MACS treatment. These authors concluded that MACS extensive use is not justified in oocyte donation programs, as this method appears to bring benefits only for some individual men. This is the largest randomized control trial with live birth that has been informed.

The first prospective study was reported by Dirican et al. [123]. The authors evaluated the outcome of ICSI in 196 couples with oligoasthenozoospermic men, comparing MACS (122 couples) and DG (74 couples) for sperm selection. They found that sperm with higher morphological quality were selected by MACS, and their use yielded improved pregnancy and cleavage rates, also, there was a slightly higher implantation rate using this technology [123].

Sheikhi et al. [124] also showed significantly higher fertilization rates, and also increased 8-cell embryo (day 3) with non-fragmented blastomeres per oocyte, when comparing couples with unexplained infertility treated with DG-ICSI $(n=37)$ or DG-MACS-ICSI $(n=37)$. However, pregnancy and birth rates, although slightly improved in the MACS group were not statistically significant [124]. 
Troya et al. [125] studied 136 infertile couples which men showed normal semen parameters according to WHO 2010 [10] and randomly assigned them to ICSI (morphological selection of sperm), PICSI (HA binding capacity) or MACS-ICSI, always after DG. In this report, they found no differences in fertilization rates, number of embryos at day 3 , or number of freezing embryos in blastocyst stage; however clinical pregnancy rates were significantly higher in the MACS group (58.1 vs. $40.4 \%$ for PICSI and $27.3 \%$ for ICSI).

Finally, a systematic review and meta-analysis of prospective randomized trials was performed by Gil et al. [126]. The study included 499 patients from five trials, for whom MACS selection was performed upon ART. Sperm selection by MACS resulted in statistically significant increases in pregnancy rates when compared with DG and SU techniques. No difference was found between the groups in the implantation and miscarriage rates. The authors concluded that MACS appears to be a safe and efficient method for sperm selection that may improve pregnancy rates in ART.

MACS has also been used after cryopreservation, obtaining successful pregnancy results. A case report was presented in which cryopreserved spermatozoa with high DNA damage (72.5\%) from a cancer patient (stage IV non-Hodgkin's lymphoma) were selected by MACS and used for ICSI, resulting in the birth of healthy twins [127]. Also, cryopreserved sperm were used in the study by Romany et al. [122] in which they did not find improvement in pregnancy rates using MACS.

A special situation was the use of MACS to select sperm obtained by testicular sperm aspiration (TESA) before ICSI [128]. It is a case report in which the born child was examined at the age of 4, finding normal development. As apoptosis begins already in the testicles $[129,130]$, it would be important to further study the use of MACS in combination with TESA.

\section{Key Issues}

- Although MACS is a novel and promising new technology for sperm selection, the improvement in ART success is still under debate. Most of studies have different experimental design, inclusion criteria and also population size. To confirm or refute the use of MACS in clinical practice, controlled and randomized studies, will be required.

- Both germ cells quality (spermatozoa and oocyte) appears to be a meaningful condition when selecting a particular subpopulation of sperm for successful fertilization. Oocytes coming from young women (i.e. oocyte donation program) show better capability for repairing certain amount of sperm DNA damage, characteristic of apoptosis. Thus, when the damage in sperm is not severe and oocytes are of good quality, MACS use doesn 't seem to be justified.

- When sperm are severely affected with extreme DNA damage, such as varicocele or environmental hazards, MACS seems to be an option of choice.

- Although the procedure itself seems not to affect sperm function, a decrease in the proportion of motile spermatozoa has been described, and elimination of EPS sperm from samples also removes capacitating sperm, with improved fertilizing ability, does impairing ART results.

- The possible iatrogenic effects of sperm manipulation during the selection procedure and/or incubation should be considered. Although there are some case reports of healthy born children, there is not enough information about the effects of applying magnetic fields on human sperm themselves, or the possible epigenetic impact on the offspring; this should be deeply investigated.

- Future efforts should be made with the aim on identifying individual patient's susceptibility to MACS to guarantee a benefit in this sperm selection procedure before ART.

\section{Conflict Of Interest}

Authors disclose no potential conflict of interest.

\section{References}

1. Miller KF, Falcone T, Goldberg JM (1996) Variation in recovery of motile sperm after preparation by a simple percoll gradient technique. J Assist Reprod Genet 13: 485-488.

2. Yanagimachi R (1994) Mammalian fertilization: The physiology of reproduction. E. Knobil and J. Neill, Raven Press, New York.

3. Merchant R, Gandhi G, Allahbadia GN (2011) In vitro Fertilization/ intracytoplasmic sperm Injection for male infertility. Indian J Urol 27: 121-132.

4. Palermo GD, Neri QV, Hariprashad JJ, Davis OK, Veeck LL, et al. (2000) ICSI and its outcome. Semin Reprod Med 18: 161-169.

5. Dyer S, Chambers GM, de Mouzon J, Nygren KG, Zegers-Hochschild F, et al. (2016) International committee for monitoring assisted reproductive technologies world report: Assisted Reproductive Technology 2008, 2009 and 2010. Hum Reprod 31: 1588-1609.

6. European IVF-Monitoring Consortium (EIM) for the European Society of Human Reproduction and Embryology (ESHRE), Calhaz-Jorge C, de Geyter C, Kupka MS, de Mouzon J (2016) Assisted Reproductive technology in Europe, 2012: Results generated from European registers by ESHRE. Hum Reprod 31: 1638-1652.

7. Palermo G, Joris H, Devroey P, Van Steirteghem AC (1992) Pregnancies after Intracytoplasmic injection of single Spermatozoon into an Oocyte. Lancet 340: 17-18.

8. Park YS, Lee SH, Song SJ, Jun JH, Koong MK, et al. (2003) Influence of motility on the outcome of in vitro fertilization/intracytoplasmic sperm injection with fresh vs. frozen testicular sperm from men with obstructive azoospermia. Fertil Steril 80: 526-530.

9. Shoukir Y, Chardonnens D, Campana A, Sakkas D (1998) Blastocyst development from supernumerary embryos after intracytoplasmic sperm injection: a paternal influence? Hum Reprod 13: 1632-1637.

10. World Health Organization (2010) WHO laboratory manual for the examination and processing of human semen. 5th edn. Geneva, Switzerland: WHO.

11. Chapuis A, Gala A, Ferrières-Hoa A, Mullet T, Bringer-Deutsch S, et al. (2017) Sperm quality and paternal age: effect on blastocyst formation and pregnancy rates. Basic Clin Androl 27: 2-9.

12. Esteves SC (2016) Novel concepts in male factor infertility: Clinical and laboratory perspectives. J Assist Reprod Genet 33: 1319-1335.

13. Sakkas D, Mariethoz E, Manicardi G, Bizzaro D, Bianchi PG, et al. (1999) Origin of DNA damage in ejaculated human spermatozoa. Rev Reprod 4: 31-37.

14. Sakkas D, Seli E, Bizzaro D, Tarozzi N, Manicardi GC (2003) Abnormal spermatozoa in the ejaculate: Abortive apoptosis and faulty nuclear remodelling during spermatogenesis. Reprod Biomed Online 7: 428-432.

15. Grunewald S, Reinhardt M, Blumenauer V, Said TM, Agarwal A, et al. (2009) Increased sperm chromatin decondensation in selected nonapoptotic spermatozoa of patients with male infertility. Fertil Steril 92: 572-577.

16. Albertini DF (2017) Explaining the futility of the reproductive process in humans: Past, present, and future. Hum Reprod 31: 1638-1652.

17. Agarwal A, Allamaneni SSR (2005) Sperm DNA damage assessment: A test whose time has come. Fertil Steril 84: 850-853. 
18. Borini A, Tarozzi N, Bizzaro D, Bonu MA, Fava L, et al. (2006) Sperm DNA fragmentation: paternal effect on early post-implantation embryo development in ART. Hum Reprod 21: 2876-2881.

19. Agarwal A, Cho CL, Esteves SC (2016) Should we evaluate and treat sperm DNA fragmentation? Curr Opin Obstet Gynecol 28: 164-171.

20. Agarwal A, Said TM (2003) Role of sperm chromatin abnormalities and DNA damage in male infertility. Hum Reprod Update 9: 331-345.

21. Collins JA, Barnhart KT, Schlegel PN (2008) Do sperm DNA integrity tests predict pregnancy with in vitro fertilization? Fertil Steril 89: 823-831.

22. Zhao J, Zhang Q, Wang Y, Li Y (2014) Whether sperm deoxyribonucleic acid fragmentation has an effect on pregnancy and miscarriage after in vitro fertilization/intracytoplasmic sperm injection: a systematic review and meta-analysis. Fertil Steril 102: 998-1005.

23. Evenson DP, Larson KL, Jost LK (2002) Sperm chromatin structure assay: its clinical use for detecting sperm DNA fragmentation in male infertility and comparisons with other techniques. J Androl 23: 25-43.

24. Larson-Cook KL, Brannian JD, Hansen KA, Kasperson KM, Aamold ET, et al. (2003) Relationship between the outcomes of assisted reproductive techniques and sperm DNA fragmentation as measured by the sperm chromatin structure assay. Fertil Steril 80: 895-902.

25. Bungum M, Humaidan P, Axmon A, Spano M, Bungum L, et al. (2007) Sperm DNA integrity assessment in prediction of assisted reproduction technology outcome. Hum Reprod 22: 174-179.

26. Grunewald S, Baumann T, Paasch U, Glander HJ (2006) Capacitation and acrosome reaction in nonapoptotic human spermatozoa. Ann N Y Acad Sci 1090: 138-146.

27. Sakkas D (2013) Novel technologies for selecting the best sperm for in vitro fertilization and intracytoplasmic sperm injection. Fertil Steril 99: 1023-1029.

28. Nani JM, Jeyendran RS (2001) Sperm processing: glass wool column filtration. Arch Androl 47: 15-21.

29. Sterzik K, De Santo M, Uhlich S, Gagsteiger F, Strehler E (1998) Glass wool filtration leads to a higher percentage of spermatozoa with intact acrosomes: an ultrastructural analysis. Hum Reprod 13: 2506-2511.

30. Hammadeh ME, Kühnen A, Amer AS, Rosenbaum P, Schmidt W (2001) Comparison of sperm preparation methods: Effect on chromatin and morphology recovery rates and their consequences on the clinical outcome after in vitro fertilization embryo transfer. Int J Androl 24 360-368.

31. Xue X, Wang WS, Shi JZ, Zhang SL, Zhao WQ, et al. (2014) Efficacy of swim-up versus density gradient centrifugation in improving sperm deformity rate and DNA fragmentation index in semen samples from teratozoospermic patients. J Assist Reprod Genet 31: 1161-1166.

32. Muratori M, Tarozzi N, Cambi M, Boni L, Iorio AL, et al. (2016) Variation of DNA fragmentation levels during density gradient sperm selection for assisted reproduction techniques: A possible new male predictive parameter of pregnancy? Medicine (Baltimore) 95: e3624.

33. Cicaré J, Caille A, Zumoffen C, Ghersevich S, Bahamondes L, et al. (2015) In vitro incubation of human spermatozoa promotes reactive oxygen species generation and DNA fragmentation. Andrologia 47: 861-866.

34. Cicaré J, Avila A, Caille A, Munuce MJ (2016) Incorporación del test de dispersión de la cromatina espermática al laboratorio andrológico. Revista Internacional de Andrología 14: 137-143.

35. Henkel R (2012) Sperm preparation: state of the art physiological aspects and application of advanced sperm preparation methods. Asian J Androl 14: 260-269.

36. Cayli S, Jakab A, Ovari L, Delpiano E, Celik-Ozenci C, et al. (2003) Biochemical markers of sperm function: Male fertility and sperm selection for ICSI. Reprod Biomed Online 7: 462-468.

37. Huszar G, Jakab A, Sakkas D, Ozenci CC, Cayli S, et al. (2007) Fertility testing and ICSI sperm selection by hyaluronic acid binding: clinical and genetic aspects. Reprod Biomed Online 14: 650-663.
38. McDowell S, Kroon B, Ford E, Hook Y, Glujovsky D, et al. (2014) Advanced sperm selection techniques for assisted reproduction. Cochrane Database Syst Rev 10: CD010461.

39. Erberelli RF, Salgado RM, Pereira DH, Wolff P (2017) Hyaluronan binding system for sperm selection enhances pregnancy rates in ICSI cycles associated with male factor infertility. JBRA Assist Reprod 21: 2-6.

40. Beck-Fruchter R, Shalev E, Weiss A (2016) Clinical benefit using sperm hyaluronic acid binding technique in ICSI cycles: a systematic review and meta-analysis. Reprod Biomed Online 32: 286-298.

41. Grunewald S, Miska W, Miska G, Rasch M, Reinhardt M, et al. (2007) Molecular glass wool filtration as a new tool for sperm preparation. Hum Reprod 22: 1405-1412.

42. Austin C (1952) The capacitation of the mammalian sperm. Nature 170: 326.

43. Chang M (1952) Fertilizing capacity of spermatozoa deposited into the Fallopian tubes. Nature 168: 697-698.

44. Tosti E, Ménézo Y (2016) Gamete activation: basic knowledge and clinical applications. Hum Reprod Update 22: 420-439.

45. Bailey J (2010) Review and hypothesis factors regulating sperm capacitation. Systems Biol Reprod Med 56: 334-348.

46. de Lamirande E, Jiang H, Zini A, Kodama H, Gagnon C (1997) Reactive oxygen species and sperm physiology. Rev Reprod 2: 48-54.

47. Du Plessis SS, Agarwal A, Halabi J, Tvrda E (2015) Contemporary evidence on the physiological role of reactive oxygen species in human sperm function. J Assist Reprod Genet 32: 509-520.

48. Aitken RJ, Baker MA, Nixon B (2015) Are sperm capacitation and apoptosis the opposite ends of a continuum driven by oxidative stress? Asian J Androl 17: 633-639.

49. Aitken RJ, Gibb Z, Baker MA, Drevet J, Gharagozloo P (2016) Causes and consequences of oxidative stress in spermatozoa. Reprod Fertil Dev 28: $1-10$.

50. Weng SL, Taylor SL, Morshedi M, Schuffner A, Duran EH, et al. (2002) Caspase activity and apoptotic markers in ejaculated human sperm. Mol Hum Reprod 8: 984-991.

51. de Vries KJ, Wiedmer T, Sims PJ, Gadella BM (2003) Caspaseindependent exposure of aminophospholipids and tyrosine phosphorylation in bicarbonate responsive human sperm cells. Biol Reprod 68: 2122-2134.

52. Grunewald S, Paasch U, Said TM, Sharma RK, Glander HJ, et al. (2005) Caspase activation in human spermatozoa in response to physiological and pathological stimuli. Fertil Steril 83: 1106-1112.

53. Tavalaee M, Deemeh MR, Arbabian M, Kiyani A, Nasr-Esfahani MH (2014) Relationship between fertilization rate and early apoptosis in sperm population of infertile individuals. Andrologia 46: 36-41.

54. Fraczek M, Hryhorowicz M, Gaczarzewicz D, Szumala-Kakol A, Kolanowski TJ, et al. (2015) Can apoptosis and necrosis coexist in ejaculated human spermatozoa during in vitro semen bacterial infection? J Assist Reprod Genet 32: 771-779.

55. Rescher U, Gerke V (2004) Annexins unique membrane binding proteins with diverse functions. J Cell Sci 117: 2631-2639.

56. Gerke V, Moss SE (2002) Annexins: From structure to function. Physiol Ver 82: 331-371.

57. Klee CB (1988) Ca2+-dependent phospholipid (and membrane) binding proteins. Biochemistry 27: 6645-6653.

58. Burgoyne RD, Geisow MJ (1989) The annexin family of calcium-binding proteins. Cell Calcium 10: 1-10.

59. Swairjo MA, Seaton BA (1994) Annexin structure and membrane interactions: A molecular perspective. Annu Rev Biophys Bioeng 23: 193-213.

60. Reutelingsperger CP, Hornstra G, Hemker HC (1985) Isolation and partial purification of a novel anticoagulant from arteries of human umbilical cord. Eur J Biochem 151: 625-629.

61. Tait JF, Gibson D, Fujikawa K (1989) Phospholipid binding properties of human placental anticoagulant protein-I, a member of the lipocortin family. J Biol Chem 264: 7944-7949. 
62. Andree HA, Reutelingsperger CP, Hauptmann R, Hemker HC, Hermens WT, et al. (1990) Binding of vascular anticoagulant alpha (VAC alpha) to planar phospholipid bilayers. J Biol Chem 265: 4923-4928.

63. Meers P, Daleke D, Hong K, Papahadjopoulos D (1991) Interactions of annexins with membrane phospholipids. Biochemistry 30: 2903-2908.

64. Huber R, Schneider M, Mayr I, Romisch J, Paques EP (1990) The calcium binding sites in human annexin $\mathrm{V}$ by crystal structure analysis at $2.0 \AA$ resolution. Implications for membrane binding and calcium channel activity. FEBS Lett 275: 15-21.

65. Mo Y, Campos B, Mealy TR, Commodore L, Head JF, et al. (2003) Interfacial basic cluster in annexin $\mathrm{V}$ couples phospholipid binding and trimer formation on membrane surfaces. J Biol Chem 278: 2437-2443.

66. Chen Z, Mao Y, Yang J, Zhang T, Zhao L, et al. (2014) Characterizing the binding of annexin $\mathrm{V}$ to a lipid bilayer using molecular dynamics simulations. Proteins 82: 312-322.

67. Sims PJ, Wiedmer T (2001) Unraveling the mysteries of phospholipid scrambling. Thromb Haemost 86: 266-275.

68. Kodigepalli KM, Bowers K, Sharp A, Nanjundan M (2015) Roles and regulation of phospholipid scramblases. FEBS Lett 589: 3-14.

69. Tans G, Rosing J, Thomassen MC, Heeb MJ, Zwaal RF, et al. (1991) Comparison of anticoagulant and procoagulant properties of stimulated platelets and platelet-derived microparticles. Blood 77: 2641-2648.

70. Fadok VA, Voelker DR, Campbell PA, Cohen JJ, Bratton DL, et al. (1992) Exposure of phosphatidylserine on the surface of apoptotic lymphocytes triggers specific recognition and removal by macrophages. J Immunol 148: 2207-2216.

71. Diaz C, Schroit AJ (1996) Role of translocases in the generation of phosphatidylserine asymmetry. J Membr Biol 151: 1-9.

72. Bevers EM, Williamson PL (2016) Getting to the outer leaflet: physiology of phosphatidylserine exposure at the plasma membrane. Physiol Rev 96: 605-645.

73. Gyobu S, Miyata H, Ikawa M, Yamazaki D, Takeshima H, et al. (2015) A role of TMEM16E carrying a scrambling domain in sperm motility. Mol Cell Biol 36: 645-659.

74. You L, Wang YX, Zeng Q, Li M, Huang YH, et al. (2015) Semen phthalate metabolites, spermatozoa apoptosis, and DNA damage: A cross-sectional study in China. Environ Sci Technol 49: 3805-3812.

75. Aitken RJ, Whiting S, De Iuliis GN, McClymont S, Mitchell LA, et al. (2012) Electrophilic aldehydes generated by sperm metabolism activate mitochondrial reactive oxygen species generation and apoptosis by targeting succinate dehydrogenase. J Biol Chem 287: 33048-33060.

76. Abts H, Emmerich M, Miltenyi S, Radbruch A, Tesch H (1989) CD20 positive human B lymphocytes separated with the magnetic cell sorter (MACS) can be induced to proliferation and antibody secretion in vitro. J Immunol Methods 125: 19-28.

77. Semple JW, Allen D, Chang W, Castaldi P, Freedman J (1993) Rapid separation of CD4+ and CD19+ lymphocyte populations from human peripheral blood by a magnetic activated cell sorter (MACS). Cytometry 14: 955-960.

78. Miltenyi S, Muller W, Weichel W, Radbruch A (1990) High gradient magnetic cell separation with MACS. Cytometry 11: 231-238.

79. Grunewald S, Paasch U (2013) Methods in molecular biology series. Sperm preparation and selection techniques: Sperm selection for ICSI using Annexin VJM Walker, Springer, New York Heidelberg Dordrecht, London. 257-262

80. Grunewald S, Paasch U, Glander HJ (2001) Enrichment of non-apoptotic human spermatozoa after cryopreservation by immunomagnetic cell sorting. Cell Tissue Bank 2: 127-133.

81. Paasch U, Grunewald S, Fitzl G, Glander HJ (2003) Deterioration of plasma membrane is associated with activated caspases in human spermatozoa. J Androl 24: 246-252.

82. Makker K, Agarwal A, Sharma RK (2008) Magnetic activated cell sorting (MACS): Utility in assisted reproduction. Indian J Exp Biol 46: 491-497.

83. Nadalini M, Tarozzi N, Di Santo M, Borini A (2014) Annexin V magnetic-activated cell sorting versus swim-up for the selection of human sperm in ART: Is the new approach better than the traditional one? J Assist Reprod Genet 31: 1045-1051.

84. Sahebjamei H, Abdolmaleki P, Ghanati F (2007) Effects of magnetic field on the antioxidant enzyme activities of suspension cultured tobacco cells. Bioelectromagnetics 28: 42-47.

85. Zhao G, Chen S, Wang L, Zhao Y, Wang J, et al. (2011) Cellular ATP content was decreased by a homogeneous $8.5 \mathrm{~T}$ static magnetic field exposure: role of reactive oxygen species. Bioelectromagnetics 32: 94-101.

86. Ghodbane S, Lahbib A, Sakly M, Abdelmelek H (2013) Bioeffects of static magnetic fields: Oxidative stress, genotoxic effects, and cancer studies. Biomed Res Int 2013:602987.

87. Koppenol WH (2001) The Haber-Weiss cycle-70 years later. Redox Report 6: 229-234.

88. Zhang QM, Tokiwa M, DoiT, Nakahara T, Chang PW, et al. (2003) Strong static magnetic field and the induction of mutations through elevated production of reactive oxygen species in Escherichia coli soxR. Int J Radiat Biol 79: 281-286.

89. Okano H (2008) Effects of static magnetic fields in biology: Role of free radicals. Front Biosci 13: 6106-6125.

90. Tenuzzo B, Vergallo C, Dini L (2009) Effect of 6mT static magnetic field on the bcl-2, bax, p53 and hsp70 expression in freshly isolated and in vitro aged human lymphocytes. Tissue Cell 41:169-179.

91. Walleczek J, Liburdy RP (1990) Nonthermal $60 \mathrm{~Hz}$ sinusoidal magneticfield exposure enhances $\mathrm{Ca} 2+$ uptake in rat thymocytes: dependence on mitogen activation. FEBS Lett 271: 157-160.

92. Amara S, Abdelmelek H, Garrel C, Guiraud P, Douki T, et al. (2006) Effects of subchronic exposure to static magnetic field on testicular function in rats. Arch Med Res 37: 947-952.

93. Formicki K, Sobocinski A, Winnicki A (1990) Motility of spermatozoa of Danube salmon (Huchohucho L.), exposed to magnetic field prior to activation. Pol Arch Hydrobiol 37: 439-447.

94. Lundsberg LS, Bracken MB, Belanger K (1995) Occupationally related magnetic field exposure and male subfertility. Fertil Steril 63: 384-391.

95. Tablado L, Pérez-Sánchez F, Soler C (1996) Is sperm motility maturation affected by static magnetic fields? Environ Health Perspect 104: 1212-1216.

96. Tateno H, Sumio I, Yoshifumi N, Yujiroh K, Asaka A (1998) No induction of chromosome aberrations inhuman spermatozoa exposed to extremely low frequency electromagnetic fields. Mut Res 414: 31-35.

97. Lorio R, Scrimaglio R, Rantucci E, Delle Monache S, Gaetano A, et al. (2007) A preliminary study of oscillating electromagnetic field effects on human spermatozoon motility. Bioelectromagnetics 28: 72-75.

98. Falahati S, Anvari M, Khalili M (2011) Effects of combined magnetic fields on human sperm parameters. Iran J Radiat Res 9: 195-200.

99. Prasad N, Wright DA, Forster JD (1982) Effect of nuclear magnetic resonance on early stages of amphibian development. Magn Reson Imaging 1: 35-38.

100. Yip YP, Capriotti C, Talagala SL, Yip JW (1994) Effects of MR exposure at $1.5 \mathrm{~T}$ on early embryonic development of thechick. J Magn Reson Imaging 4: 742-748.

101. Curti G, Skowronek F, Vernochi R, Rodriguez-Buzzi AL, Rodriguez-Buzzi JC, et al. (2014) Morphological evaluation of sperm from infertile men selected by magnetic activated cell sorting (MACS). Reprod Biol 14: 289-292.

102. Said TM, Grunewald S, Paasch U, Glander HJ, Baumann T, et al. (2005) Advantage of combining magnetic cell separation with sperm preparation techniques. Reprod Biomed Online 10: 740-746.

103. Chi HJ, Kwak SJ, Kim SG, Kim YY, Park JY, et al. (2016) Efficient isolation of sperm with high DNA integrity and stable chromatin packaging by a combination of density-gradient centrifugation and magnetic-activated cell sorting. Clin Exp Reprod Med 43: 199-206.

104. Bucar S, Gonçalves A, Rocha E, Barros A, Sousa M, Sá R (2015) DNA fragmentation in human sperm after magnetic-activated cell sorting. J Assist Reprod Genet 32: 147-154. 
105. Cakar Z, Cetinkaya B, Aras D, Koca B, Ozkavukcu S, et al. (2016) Does combining magnetic-activated cell sorting with density gradient or swimup improve sperm selection? J Assist Reprod Genet 33: 1059-1065.

106. Delbes G, Herrero MB, Troeung ET, Chan PT (2013) The use of complimentary assays to evaluate the enrichment of human sperm quality in asthenoteratozoospermic and teratozoospermic samples processed with Annexin- $\mathrm{V}$ magnetic activated cell sorting. Andrology 1: 698-706.

107. de VantéryArrighi C, Lucas H, Chardonnens D, de Agostini A (2009) Removal of spermatozoa with externalized phosphatidylserine from sperm preparation in human assisted medical procreation: Effects on viability, motility and mitochondrial membrane potential. Reprod Biol Endocrinol 7: 1-12.

108. Lee TH, Liu CH, Shih YT, Tsao HM, Huang CC, et al. (2010) Magneticactivated cell sorting for sperm preparation reduces spermatozoa with apoptotic markers and improves the acrosome reaction in couples with unexplained infertility. Hum Reprod 25: 839-846.

109. Tavalaee M, Deemeh MR, Arbabian M, Nasr-Esfahani MH (2012) Density gradient centrifugation before or after magnetic-activated cell sorting: Which technique is more useful for clinical sperm selection? J Assist Reprod Genet 29: 31-38.

110. Vendrell X, Ferrer M, Garcia-Mengual E, Munoz P, Trivino JC, et al. (2014) Correlation between aneuploidy, apoptotic markers and DNA fragmentation in spermatozoa from normozoospermic patients. Reprod Biomed Online 28: 492-502.

111. Said TM, Agarwal A, Grunewald S, Rasch M, Baumann T, et al. (2006) Selection of nonapoptotic spermatozoa as a new tool for enhancing assisted reproduction outcomes: An in vitro model. Biol Reprod 74: 530-537.

112. Degheidy T, Abdelfattah H, Seif A, Albuz FK, Gazi S, et al. (2015) Magnetic activated cell sorting: An effective method for reduction of sperm DNA fragmentation in varicocele men prior to assisted reproductive techniques. Andrologia 47: 892-896.

113. Wang YX, Sun Y, Huang Z, Wang P, Feng W, et al. (2016) Associations of urinary metal levels with serum hormones, spermatozoa apoptosis and sperm DNA damage in a Chinese population. Environ Int 94: 177-188.

114. Wang YX, Zeng Q, Sun Y, You L, Wang P, et al. (2016) Phthalate exposure in association with serum hormone levels, sperm DNA damage and spermatozoa apoptosis: A cross-sectional study in China. Environ Res 150: 557-565.

115. Said TM, Grunewald S, Paasch U, RaschM, Agarwal A, et al. (2005) Effects of magnetic-activated cell sorting on sperm motility and cryosurvival rates. Fertil Steril 83: 1442-1446.

116. Grunewald S, Paasch U, Said TM, Rasch M, Agarwal A, et al. (2006) Magnetic-activated cell sorting before cryopreservation preserves mitochondrial integrity in human spermatozoa. Cell Tissue Bank 7: 99-104.

117. Paasch U, Grunewald S, Wuendrich K, Jope T, Glander HJ (2005) Immunomagnetic removal of cryo-damaged human spermatozoa. Asian J Androl 7: 61-69.
118. Rawe VY, Boudri HU, Alvarez Sedo C, Carro M, Papier S, et al. (2010) Healthy baby born after reduction of sperm DNA fragmentation using cell sorting before ICSI. Reprod Biomed Online 20: 320-323.

119. Polakde FE, Denaday F (2010) Single and twin ongoing pregnancies in two cases of previous ART failure after ICSI performed with sperm sorted using annexin V microbeads. Fertil Steril 94: 351.e15-8.

120. Marchetti F, Essers J, Kanaar R, Wyrobek AJ (2007) Disruption of maternal DNA repair increases sperm-derived chromosomal aberrations. Proc Natl Acad Sci USA 104: 17725-17729.

121. Meseguer M, Santiso R, Garrido N, García-Herrero S, Remohí J, et al. (2011) Effect of sperm DNA fragmentation on pregnancy outcome depends on oocyte quality. Fertil Steril 95: 124-128.

122. Romany L, Garrido N, Motato Y, Aparicio B, Remohí J, et al. (2014) Removal of annexin V-positive sperm cells for intracytoplasmic sperm injection in ovum donation cycles does not improve reproductive outcome: A controlled and randomized trial in unselected males. Fertil Steril 102: 1567-1575.

123. Dirican EK, Ozgün OD, Akarsu S, Akin KO, Ercan O, et al. (2008) Clinical outcome of magnetic activated cell sorting of non-apoptotic spermatozoa before density gradient centrifugation for assisted reproduction. J Assist Reprod Genet 25: 375-381.

124. Sheikhi A, Jalali M, Gholamian M, Jafarzadeh A, Jannati S, et al. (2013) Elimination of apoptotic spermatozoa by magnetic activated cell sorting improves the fertilization rate of couples treated with ICSI procedure. Androl 1: 845-849.

125. Troya J, Zorrilla I (2015) Annexin V-MACS in infertile couples as method for separation of sperm without DNA fragmentation. JBRA Assist Reprod 19: 66-69.

126. Gil M, Sar-Shalom V, Melendez SY, Carreras R, Checa MA (2013) Sperm selection using magnetic activated cell sorting (MACS) in assisted reproduction: A systematic review and meta-analysis. J Assist Reprod Genet 30: 479-485.

127. Herrero MB, Delbes G, Chung JT, Son WY, Holzer H, et al. (2013) Case report: the use of annexin $\mathrm{V}$ coupled with magnetic activated cell sorting in cryopreserved spermatozoa from a male cancer survivor: Healthy twin newborns after two previous ICSI failures. J Assist Reprod Genet 30: 1415-1419.

128. Lukaszuk K, Wcislo M, Liss J, Stachowicz A, Jakiel G, et al. (2015) First pregnancy, somatic and psychological status of a 4-year-old child born following Annexin V TESA sperm separation. AJP Rep 5: 105-108.

129. Bonnie HY, Yeung B, Wan H, Law A, Wong C (2011) Endocrine disrupting chemicals. Multiple effects on testicular signaling and spermatogenesis. Spermatogenesis 1: 231-239.

130. Pointis G, Gilleron J, Carette D, Segretain D (2011) Testicular connexin 43 , a precocious molecular target for the effect of environmental toxicants on male fertility. Spermatogenesis 1: 303-317. 